\title{
Negative Ion Electrospray Mass Spectrometry of Nucleotides: Ionization from Water Solution with $\mathrm{SF}_{6}$ Discharge Suppression
}

\author{
Francis M. Wampler III, Arthur T. Blades, and Paul Kebarle \\ Department of Chemistry, University of Alberta, Edmonton, Alberta, Canada
}

\begin{abstract}
The total current and selected ion currents from the electrospray ionization (ESI) of $10^{-5} \mathrm{M}$ solutions of cocaine hydrochloride and deoxycytidine monophosphate (dCMP) monosodium salt in methanol and water solvents were compared in positive and negative ion modes, respectively, without and with $\mathrm{SF}_{6}$ gas as a discharge suppressant. The ESI onset voltages $\left(V_{\text {on }}\right)$, were the same for the positive and negative ion modes. The $V_{\text {on }}$ for methanol was much lower than that for water and in agreement with the equation of D. P. H. Smith, who attributes the difference to the higher surface tension of water. The onset of electric discharge $\left(V_{\mathrm{dis}}\right)$ without $\mathrm{SF}_{6}$ occurred at lower capillary voltages for the negative relative to the positive ion mode for methanol; but $V_{\text {dis }}$ is much higher than $V_{\text {on }}$ for methanol, and discharges do not interfere with ESI operation. For water, $V_{\text {on }} \approx V_{\text {dis }}$ in the absence of $\mathrm{SF}_{6}$ in the negative ion mode, and ESI operation is impossible without $\mathrm{SF}_{6}$ discharge suppression. The discharge problem in the positive ion mode is less severe, but $\mathrm{SF}_{6}$ is still very useful. A dynamic range of $10^{-7}-10^{-5} \mathrm{M}$ was obtained by selected ion monitoring of $[\mathrm{dCMP}-\mathrm{H}]^{-}$at 4.5 and 20 $\mu \mathrm{L} / \mathrm{min}$. flows. Subpicomole detection limits for the nucleotide salt were obtained under these conditions. (J Am Soc Mass Spectrom 1993, 4, 289-295)
\end{abstract}

W e are interested in the potential of negative ion electrospray ionization/mass spectrometry) (ESI/MS) for the analysis of nucleoside/nucleotide mixtures by capillary electrophoresis/ MS and microbore high-performance liquid chromotography (HPLC)/MS.

The negative ion mode (NIM) has been used for ESI/MS of oligonucleotide anions in solution [1-3]. By contrast, ESI/MS analysis of monomeric nucleotides has received little attention. Fenn and co-workers $[4,5]$ have provided some NIM spectra for these compounds, but most of the reported ESI mass spectra of single nucleotides $[2,5]$ were obtained in the positive ion mode. Identification of many analytes by HPLC/MS separations of monomeric nucleoside/ nucleotide mixtures has been performed by thermospray/MS [6].

The extensive solution ionization of nucleoside monophosphates, diphosphates and triphosphates requires close to $100 \%$ aqueous mobile phase to allow their reversed-phase HPLC or ion-exchange chromatographic separation [7]. The ESI/MS of highly aqueous

Address reprint requests to Iaul Kebarle, Department of Chemistry, University of Alberta, Edmonton, Canada, T6G $2 \mathrm{G} 2$. solutions poses problems. The high electric field necessary for droplet formation at the ESI spray tip for high surface tension liquids (i.e., water) can initiate corona discharge [8].

The sheath flow ESI device of R. D. Smith et al. $[1,9]$ appears to perform well for mononucleotides and oligonucleotide in the NIM, as does Henion's "ionspray" $[3,10]$; however, the minimum solution organic content for which ESI mass spectra were shown was $5 \%$ acetonitrile [10] in the citations from these investigators [1, 3, 9-12]. Chowdhury and Chait [13] demonstrated that stable ESI currents were obtained for pure aqueous solutions with a specially sharpened and electropolished spray tip in air without nebulization assistance. This study showed ESI mass spectra for horse heart cytochrome $c$ in aqueous solution containing 0.01-3\% acetic acid levels, but all results were for the positive ion mode.

Yamashita and Fenn [14] observed that the onset of corona discharge occurs at significantly lower field strengths for negative versus positive ion ESI/MS operation. They suggested that the introduction of a high electron affinity gas over the spray tip would be helpful in suppressing discharge. The gases reported in this role to date include $\mathrm{O}_{2}$ [14], $\mathrm{N}_{2}$ doped with freon [12], and $\mathrm{SF}_{6}[15]$. 
Ikonomou et al. [15] provided comprehensive data on the effects of $\mathrm{SF}_{6}$ discharge suppression for positive ion ESI/MS of cocaine/HCI in $99 \%$ water $/ 1 \%$ methanol, and we present here the results of subsequent work, showing the successful corona discharge suppression by $\mathrm{SF}_{6}$ for the negative ion ESI/MS of the DNA nucleoside 5'-monophosphate salts from pure aqueous solutions.

Very recently, R. D. Smith and co-workers [16] reported a study of multiply negatively charged polypeptides and proteins resulting from the deprotonation in basic solution of peptides or proteins with multiple acid functions. Although these workers used the sheath flow device [1,9], they found it advantageous to also use $\mathrm{SF}_{6}$ gas flow with the sheath flow. This indicates that the use of $\mathrm{SF}_{6}$ for discharge suppression may become widespread in the future, particularly for work with aqueous solutions and in the NIM.

\section{Experimental}

The instrument used in this study was a triple quadrupole mass spectrometer (TAGA Model 6000E; Sciex) equipped with an ESI source in the atmospheric pressure plenum chamber [17]. The source [17] and the ESI sprayer assembly [15] have been described in detail elsewhere. Briefly, the analyte solution is electrosprayed at the tip of a [0.1-mm inuer dianleter (id), $0.23-\mathrm{mm}$ outer diameter (od)] stainless steel capillary. The $\mathrm{SF}_{6}$ gas is conducted through the arnular space between an uuter tube $(1.6-\mathrm{mm}$ od, $1.3-\mathrm{mm}$ id) and the inner capillary to "blanket" the ESI tip. The capillary protruded $4.4 \mathrm{~mm}$ beyond the outer tube. Analyte solution was supplied to the capillary through $0.075-$ $\mathrm{mm}$ id, $0.275-\mathrm{mm}$ od fused-silica tubing joined to the capillary by means of a zero dead volume union. Solutions were supplied by continuous infusion to the sprayer from a motor-driven syringe. The flow rates were $20 \mu \mathrm{L} / \mathrm{min}$ (unless otherwise indicated), and the solvents were various methanol/water mixtures and the pure liquids. The methanol was reagent grade, redistilled with $\mathrm{H}_{3} \mathrm{PO}_{4}$ to remove any amine impurities. The water $\left(\mathrm{H}_{2} \mathrm{O}\right)$ was doubly-deionized by treatment in a Millipore MLLLI-Q water purification system $\left(6 \times 10^{6} \Omega^{-1} \mathrm{~m}^{-1}\right)$. The solvent compositions are given in volume percent. The $\mathrm{SF}_{6}$ used was a chemically pure grade from LINDE.

The $\mathrm{SF}_{6}$ flow used was $200 \mathrm{~mL} / \mathrm{min}$ [15]. The relatively wide i.d. of the $\mathrm{SF}_{6}$ sleeve led to low $\mathrm{SF}_{6}$ gas velocities near the inner capillary tip. This slow flow suppressed corona discharge while avoiding nebulization, thus attaining minimal disturbance of conventional ESI conditions. An ambient air flow of approximately $500 \mathrm{~mL} / \mathrm{s}$ was maintained through the atmospheric pressure plenum chamber.

The ESI sprayer assembly was mounted inside the plenum chamber. The capillary tip-to-interface plate wall separation distance was $4 \mathrm{~cm}$, and the capillary was $0.5 \mathrm{~cm}$ off-axis from the 4- $\mathrm{mm}$-diameter orifice in the interface plate.

The $4-\mathrm{cm}$ distance between capillary tip and the counterelectrode (interface plate) is larger than distances used in other laboratories. We use a larger distance because it reduces the penetration of unevaporated droplets into the interface chamber. Other interfaces handle that problem in different ways. The larger electrode distance necessitates larger capillary potentials for ESI; however, this does not mean that the present arrangement is more prone to electric discharge. To obtain a given electrospray emission, a given electric field is required. If the required electric field is too high, as in the case for water, then an electric discharge will occur. Although the voltages with different electrode arrangements will differ, the required electric field for ESI at the tip will be the same. Therefore, the results presented in this work also remain relevant for other interfaces that use lower capillary voltages and shorter distances.

The electric fields driving the electrospray and the corona discharge are dependent on the potential difference between the capillary tip and the large counterelectrode (interface plate). Therefore, all the capillary voltages quoted correspond to that potential difference and not to the capillary potential relative to ground. The capillary potential relative to ground is $650 \mathrm{~V}$ higher because the interface plate is at $650 \mathrm{~V}$ relative to ground.

\section{Results and Discussion}

\section{Corona Discharge in Ambient Air and Its Suppression}

Because one objective was to examine the extent of discharge suppression by $\mathrm{SF}_{6}$ in $\mathrm{ESI}$ of methanol and water solutions, it was found useful to examine the nature of the discharge-produced ions in ambient air when the capillary and capillary tip are dry (i.e,, in a conventional corona discharge originating at the capillary tip).

A relatively steady discharge current of $3 \times 10^{-8} \mathrm{~A}$ was obtained at $-3.4 \mathrm{kV}$. The major ions observed were at $m / z 32\left(\mathrm{O}_{2}^{-}\right), 45\left[\mathrm{HCO}_{2}^{-}\right.$(formate)], $46\left[\mathrm{NO}_{2}^{-}\right.$ (most intense), $62\left(\mathrm{NO}_{3}^{-}\right)$, and $89\left[\mathrm{CH}_{3} \mathrm{CHOHCO}_{2}^{-}\right.$ (lactate?)]. These are similar to the background ions observed by Yamashita and Fenn [14] $\left.\mathrm{CO}_{2}^{-}, \mathrm{NO}_{2}^{-}, \mathrm{O}_{3}^{-}\right)$ and Henion and co-workers [12] $\left[\mathrm{HCO}_{2}^{-}, \mathrm{CH}_{3} \mathrm{CO}_{2}^{-}\right.$ (acetate), $\mathrm{NO}_{3}^{-}$and $\mathrm{CH}_{3} \mathrm{CHOHCO}_{2}^{-}$(lactate)] for NIM electrospray, respertively.

An increase in the capillary voltage in the present work to $-5.4 \mathrm{kV}$ led to a total current of $1.9 \times 10^{-6} \mathrm{~A}$ and the negative ion spectrum shown in Figure 1a. The intensities of all of the ions observed at the lower voltage increased, as shown in Figure $1 \mathrm{a}$. In addition, ions at $\mathrm{m} / \mathrm{z} 16\left(\mathrm{O}^{-}\right), 17\left(\mathrm{OH}^{-}\right), 60\left(\mathrm{CO}_{3}^{-}\right), 61\left(\mathrm{HCO}_{3}^{-}\right)$ and $77\left(\mathrm{HCO}_{4}^{-}\right)$became prominent. These species are 

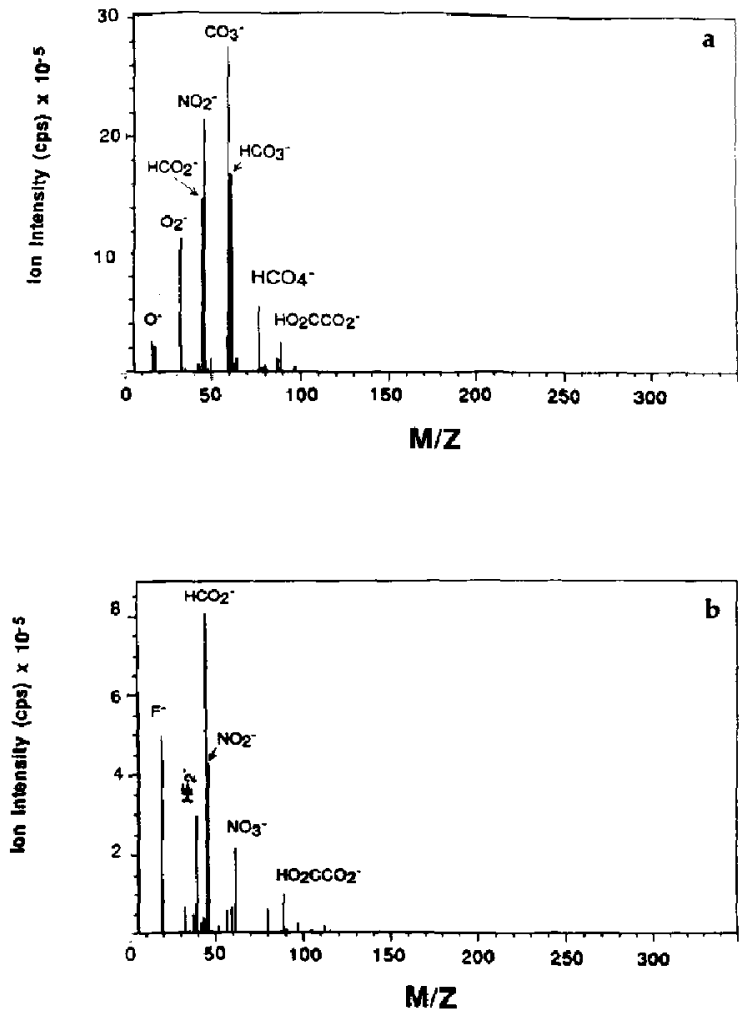

Figure 1. Mass spectra observed in the presence of electric discharge when the capillary tip was dry. (a) Mass spectra were obtained in the absence of $\mathrm{SF}_{6}$ flow; capillary voltage $V_{s}-\cdots 5.4$ $\mathrm{kV} ; \mathrm{TC}=1.9 \times 10^{-6} \mathrm{~A}$. Ions observed are typical discharge ions. (b) Mass spectra were obtained with $\mathrm{SF}_{\mathrm{b}}$ flow; $V_{\mathrm{c}}=-5.4 \mathrm{kV}$; $\mathrm{TC}=3 \times 10^{-8} \mathrm{~A}$.

all consistent with what is known about negative ion chemistry in the troposphere and ionosphere $[18,19]$.

In the presence of $\mathrm{SF}_{6}$ flow at $200 \mathrm{~mL} / \mathrm{min}$, the onset of the discharge increased from -3.4 to -5.0 $\mathrm{kV}$. A mass spectrum obtained at $-5 \mathrm{kV}$ with $\mathrm{SF}_{6}$ is shown in Figure $1 \mathrm{~b}$. The total current at $-5 \mathrm{kV}$ dropped from $1.9 \times 10^{-6}$ to $3.0 \times 10^{-8} \mathrm{~A}$ in the presence of $\mathrm{SF}_{6,}$, and the total intensity of the ions (Figure 1b) became much lower. The relative ion intensities of $\mathrm{O}^{-}, \mathrm{O}_{2}^{-}$, and $\mathrm{NO}_{2}^{-}$are considerably reduced in the presence of $\mathrm{SF}_{6}$, whereas some new $\mathrm{SF}_{6}$-derived ions $\left(\mathrm{F}^{-}\right.$and $\left.\mathrm{HF}_{2}^{-}\right)$ appeared. The change is in line with the expected interception of electrons by $\mathrm{SF}_{6}$, which disrupts the electron "avalanche ${ }^{\prime \prime}[20]$. The $\mathrm{SF}_{6}^{-}$formed by electron capture [20] is not observed in the spectrum (Figure 2b). Grimsrud and co-workers [21b] showed that $\mathrm{SF}_{6}^{-}$ in the presence of $\mathrm{H}_{2} \mathrm{O}$ is converted to $\mathrm{F}^{-}$, and it is probably largely this reaction that removes the $\mathrm{SF}_{6}^{-}$ and leads to the observed $\mathrm{F}^{-}$.

The results above demonstrate that at lower capillary voltages, $\mathrm{SF}_{6}$ can lead to complete suppression of the discharge. At higher voltages, such as $-5.4 \mathrm{kV}$, a very large reduction in the discharge still occurs, lead- ing to current decreases by a factor of approximately 60 , but a total suppression is not achieved.

The onset of electric discharge in the positive ion mode (PIM) was also determined with a dry capillary. Several tests in the absence of $\mathrm{SF}_{6}$ showed that the PIM onset occurs at potentials higher by approximately 600 $V$ relative to the onset in the NIM. The onset of electric discharge observed with a dry capillary for NIM and PIM is summarized in Table 1. The nature of positive ions formed by electric discharge in air has been described in previous work [15].

\section{Mass Spectra and ESI Analyte Ion Mass Spectral Detection: Electric Discharge Characteristics}

Mass spectra obtained from solutions of $10^{-4} \mathrm{M}$ deoxycitidine monophosphate monosodium salt (NadCMP) in $100 \% \mathrm{H}_{2} \mathrm{O}$ at $-4.4 \mathrm{kV}$ without and with $200 \mathrm{~mL} / \mathrm{min} \mathrm{SF}_{6}$ flow are shown in Figure 2. The structure of the $\left[\mathrm{dCMP}-\mathrm{II}^{-}\right.$anion, formed by the near- $100 \%$ dissociation of NadCMP in aqueous solution, is shown in Structure 1.

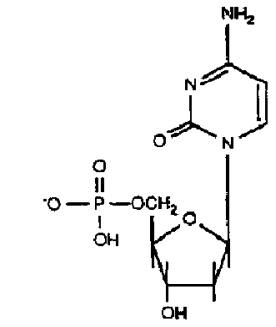

2'-Deoxycytidine-5'-monophosphate (ACMP-H) 306 amb

1

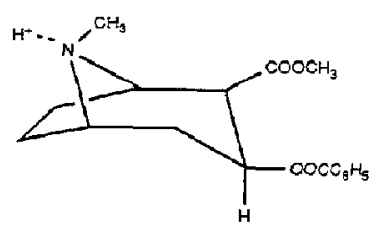

Cocaine $\mathrm{H}^{-} \quad 3 \mathrm{C} 4 \mathrm{amu}$

2
The spectrum without $\mathrm{SF}_{6}$ (Figure $2 \mathrm{a}$ ) contains the same ions as were observed from the dry capillary discharge (Figure 1a). Notable is the complete absence of the ESI analyte ion $[\mathrm{dCMP}-\mathrm{H}]^{-}$. In the presence of $\mathrm{SF}_{6}$ (Figure $2 \mathrm{~b}$ ), the total intensity of the discharge ions

Table 1. Electrospray and Electric Discharge Onsel Voltages for Methanol and Water ${ }^{a}$

\begin{tabular}{|c|c|c|c|c|c|}
\hline Solvent & Mode & $\begin{array}{c}V_{\text {on }} \\
\text { theory } \\
\text { (kV) }\end{array}$ & $V_{\text {on }}(\mathrm{kV})$ & $V_{\text {dis }}(k V)$ & $\begin{array}{c}V_{\text {dis }}\left(\mathrm{SF}_{6}\right) \\
(\mathrm{kV})\end{array}$ \\
\hline \multirow[t]{2}{*}{ Methanol } & NIM & -2.2 & -2.1 & -3.6 & -4.5 \\
\hline & PIM & +2.2 & +2.1 & +4.6 & +6.0 \\
\hline \multirow[t]{2}{*}{ Water } & NIM & -4.0 & $-3.7^{b}$ & са. $-\mathbf{3 . 7}$ & $\mathrm{ca}-4.5$ \\
\hline & PIM & +4.0 & $+3.8^{b}$ & $\mathrm{ca}+4.0$ & ca. +5.5 \\
\hline \multirow[t]{2}{*}{ Dry capillary } & NIM & - & 一 & -3.4 & -5.0 \\
\hline & PIM & - & - & +4.0 & $N D^{c}$ \\
\hline
\end{tabular}

\footnotetext{
$V_{o n}$ onset of electrospray; $V_{\text {dis }}$ anset of electric discharge; potentials quoted are relative to counterelectrode (interface plate), which is at $+650 \mathrm{VPIM}$ and $-650 \mathrm{~V}$ NIM relative to ground.

Determined in the presence of $\mathrm{SF}_{6}$ flow

ND, was not determined.
} 

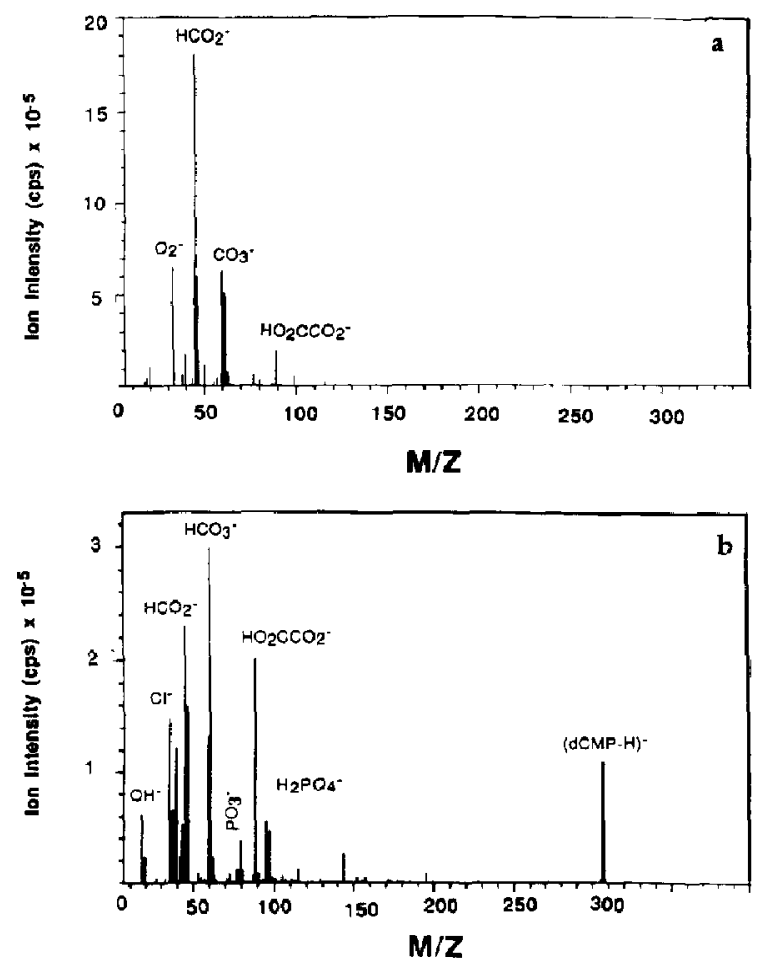

Figure 2. Mass spectra obtained from ESI of $10^{-4} \mathrm{M}$ solutions of NadCMP in $100 \%$ water at $V_{c}=-4.4 \mathrm{kV}$. (a) Without $\mathrm{SF}_{6}$ flow no analyte ion can be detected; (b) with $200 \mathrm{~mL} / \mathrm{min} \mathrm{SF}_{6}$ flow, the anion $[\mathrm{dCMP}-\mathrm{H}]^{-}$is detected.

has decreased by a factor of approximately 10 , and $\left[\mathrm{dCMP}-\mathrm{H}^{-}\right.$is present with substantial intensity.

The total current (TC) to the counterelectrode (interface plate) and the intensity dependence of selected ions plotted versus the capillary voltage are shown in Figures 3 and 4 . The results provide data illustrating the effect of the $\mathrm{SF}_{6}$ flow on ESI in the NIM with $10^{-5}$ $M$ NadCMP with methanol and water as solvents. From Figures 3 and 4 one can deduce three capillary voltage $\left(V_{c}\right)$ potentials that are of interest: onset of electrospray $\left(V_{\text {on }}\right)$; onset of electric discharge in the absence of $\mathrm{SF}_{6}\left(V_{\mathrm{dis}}\right)$; and onset of discharge in the presence of $\mathrm{SF}_{6}\left[V_{\mathrm{dis}}\left(\mathrm{SF}_{6}\right)\right], V_{\text {on }}$ was chosen as the point at which there is a sudden appearance of TC. A sharp onset is also observed in the intensity of analyte ions at a potential that is very close to that indicated by the TC. The average $V_{\text {on }}$ values are summarized in Table 1.

Also included in Table 1 for comparison are the corresponding potentials for the PIM mode where cocaine $\mathrm{HCl}$ (2) was used as analyte. These data were obtained on the basis of measurements performed in the present work under exactly the same conditions as the NIM experiments. The PIM experiments were a duplication of the earlier work [15], and because the results were very close to those obtained earlier (see
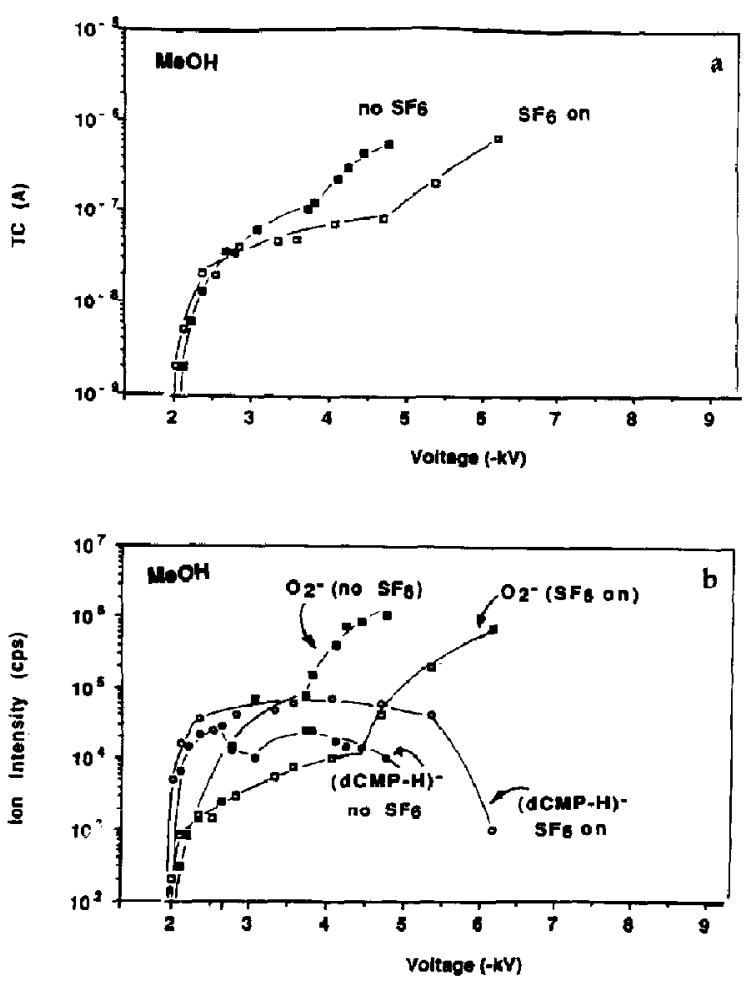

Figure 3. (a) Capillary TC; (b) mass-analyzed ions. Both were observed with $10^{-5} \mathrm{M}$ solutions of NadCMP in methanol (MeOH) in the NIM without and with $\mathrm{SF}_{6}$ gas and plotted versus capil-

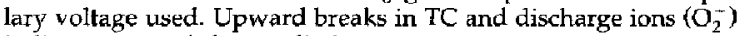
indicate onset of electric discharge.

Figures 5 and 6 in ref 15), no additional experimental documentation is provided here.

The $V_{\mathrm{on}}$ for NIM and PIM is seen to be identical when the same solvent is used. As discussed previously [15], the much higher $V_{\text {on }}$ for water is due to the much higher surface tension of water. The $V_{\text {on }}$ can be predicted by eq 1 , derived by Smith [8],

$$
V_{\text {on }}=\left(\frac{y r_{\mathrm{c}} \cos \theta}{2 \epsilon_{\mathrm{o}}}\right)^{1 / 2} \ln \left(4 d / r_{\mathrm{c}}\right)
$$

where $\gamma$ is the surface tension (for $\mathrm{H}_{2} \mathrm{O}, \gamma=0.073 \mathrm{~N}$ $\mathrm{m}^{-1}$; for $\mathrm{CH}_{3} \mathrm{OH}, \gamma=0.0224 \mathrm{~N} \mathrm{~m}^{-1}$ ); $\theta=49.3^{\circ}$ (halfangle of Taylor cone); $\epsilon_{0}=8.8 \times 10^{-12} \mathrm{~J}^{-1} \mathrm{C}^{2} \mathrm{~m}^{-1}$ (permittivity of vacuum); $d=0.04 \mathrm{~m}$ (distance between capillary tip and counterelectrode), and $r_{\mathrm{c}}=$ $1.15 \times 10^{-4} \mathrm{~m}$ (outer radius of capillary tip).

Smith's derivation of eq 1 is not dependent on the sign of the charged droplets formed, which means that the $V_{o n}$ should be the same for NIM and PIM when the same solvent is used. The values for $V_{\text {on }}$ predicted by eq 1 for the present experimental conditions are shown in Table 1 and are seen to be in good agreement with the experimental results. 

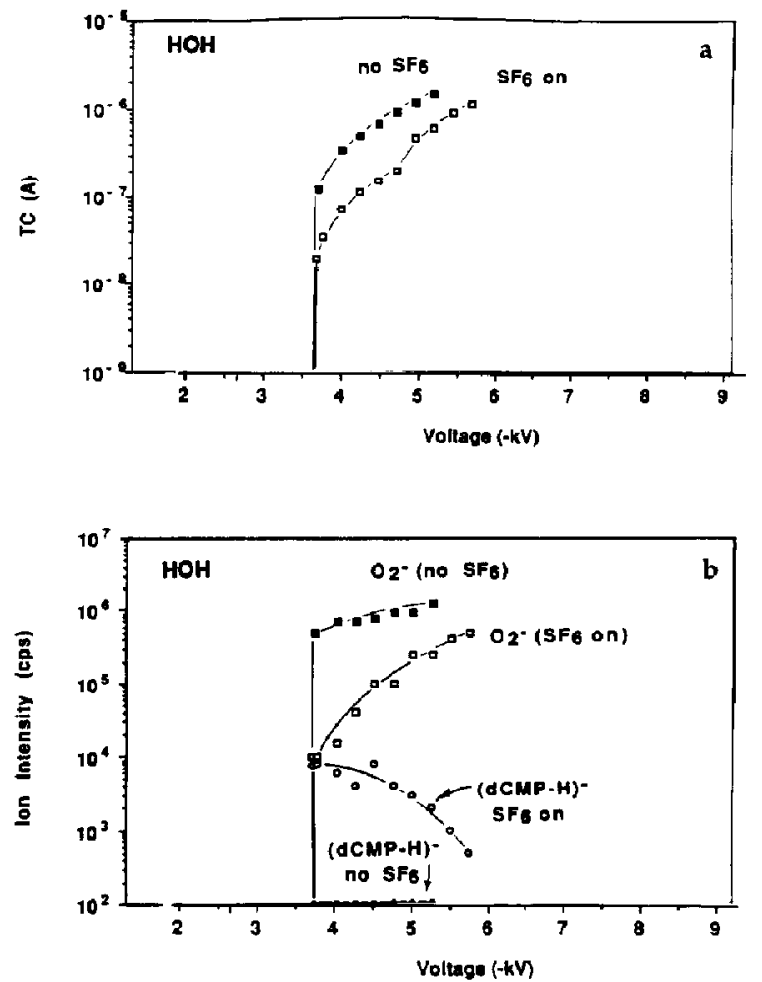

Figure 4, Capillary TC and mass-analyzed ions from $10^{-5} \mathrm{M}$ solutions NadCMP in water (HOH), NIM. ESI onset for water occurs at higher capillary voltage, where an electric discharge also occurs. No analyte ion can be observed without $\mathrm{SF}_{6}$. The presence of $\mathrm{SF}_{6}$ allows detection of analyte ion

As in the previous work [15], we select for $V_{\mathrm{dis}}$ the potential at which an upward break is observed in the TC. These breaks are not always distinct. The curves for the discharge-indicating ions provide additional information. The choice of $\mathrm{O}_{2}^{-}$as the dischargeindicating ion for NIM is justified by the dry discharge mass spectra (see Figure 2a). The discharge-indicating ions for NIM and PIM in methanol [15] show discharge breaks at the same position as the $\mathrm{TC}$ break, and therefore the determination of $V_{\mathrm{dis}}$ and $V_{\mathrm{dis}}\left(\mathrm{SF}_{6}\right)$ for methanol NIM and PIM is unambiguous (see Figure 3) (see also Figure 5 in ref 22). The $V_{\text {dis }}$ values for methanol are given in Table 1.

Because the electrospray onset $V_{\text {or }}$ for methanol is low, the electric discharge occurs relatively late, and discharge interference is not a serious problem for PIM or NIM in methanol. Some differences between NIM and PIM should be noted. The discharge occurs later for PIM: $V_{\text {dis }}=4.6 \mathrm{kV}$ (PIM); $V_{\text {dis }}=3.6 \mathrm{kV}$ (NIM). $\mathrm{SF}_{6}$ flow delays the discharge by $1.5 \mathrm{kV}$ for PIM and only $1.0 \mathrm{kV}$ for NIM. A later onset of discharge from PIM was also observed with the dry capillary. As was the case for the dry capillary, the earlier occurrence of discharge for NiM is probably due to discharge onset by field emission of electrons from fine tips and "whiskers" at the capillary tip. This type of charge emission is not possible for PIM.

At higher discharge currents where TC $>0.5 \mu \mathrm{A}$, decreases of the analyte ion intensities are observed for NIM (see Figure 3) and PIM (see Figure 5 in ref 15). Because of the earlier onset of discharge for NIM, the analyte intensity decrease occurs earlier for NIM; however, for both PIM and NIM in methanol there is a plateau region in analyte ion intensity at lower voltages, particularly in the presence of $\mathrm{SF}_{6}$, which allows a comparison of the analyte ion intensities in the absence of discharge. This "best" analyte ion intensity is much higher for the PIM analyte [cocaine $+\mathrm{H}]^{+}$, approximately $4 \times 10^{5} \mathrm{HZ}$ [15] relative to the NIM [dCMP $-\mathrm{H}]^{-}$ion, approximately $5 \times 10^{4} \mathrm{HZ}$. Massdependent quadrupole transmission cannot be responsible for this difference because the two ions have nearly the same mass, $m / z 304$ and 306. Probably, the intensity disparity is also not due to other NIM versus PIM differences. Most likely involved are the different structures of the ions, (see structures 1 and 2) [dCMP $-\mathrm{Hl}^{-}$has more polar, hydrogen-bonding groups than [cocaine $+\mathrm{H}]^{+}$. A lower efficiency for the electrospray conversion of ions in solution to ions in the gas phase is expected for the more polar, hydrophilic ions such as $\left[\mathrm{dCMP}-\mathrm{H}^{-}[22,23]\right.$.

The onset of electrospray in water requires a much higher potential $\left(V_{\text {on }} \approx 3.8 \mathrm{kV}\right)$, which is in the region of discharge onset with a dry capillary $\left(V_{\text {dis }} \approx 3.4 \mathrm{kV}\right.$ NIM, $4 \mathrm{kV}$ PIM; Table 1). Therefore the occurrence of discharge close to the electrospray onset, observed in Figure 4 for NIM (and in Figure 6 in ref 15 for P'IM) is not surprising. In the absence of $\mathrm{SF}_{6}$, the discharge interference is far more pronounced for NIM. This is clearly indicated by the much higher discharge-ion intensity $\left(\mathrm{O}_{2}^{-} \sim 10^{6} \mathrm{HZ}\right)$ at the onset for NIM relative to $\mathrm{CH}_{3} \mathrm{OH}_{2}^{+}$intensity of approximately $10^{4} \mathrm{HZ}$ at onset for PIM [15]. The analyte ion is completely suppressed by the discharge for NIM, whereas a good analyte ion intensity is observed for PIM [15]. Therefore the application of $\mathrm{SF}_{6}$ is absolutely essential for NIM, whereas for PIM, the presence of $\mathrm{SF}_{6}$ is beneficial but not essential.

The TCs and the discharge-ion intensities indicate that $\mathrm{SF}_{6}$ is more effective in suppressing the discharge for PIM relative to NIM. This effect may also be due to field emission of electrons in NIM. The electrons emitted at the sharp points are exposed to very high electric fields and will accelerate rapidly to high velocities, where electron capture by $\mathrm{SF}_{6}$ is less efficient.

As noted above, the presence of discharge current reduces the intensities of ESI-produced ions. This is evident for both NIM and PIM in methanol and water (Figures 3 and 4 and ref 15). In our previous work [15], we attributed this adverse effect to the increased space charge at higher currents. The presence of space charge in the vicinity of the interface plate and sampling orifice may be expected to reduce the fraction of ions that enter the mass analysis region. Fenn et al. [24] 
suggested another possible cause. The presence of electric discharge reduces the electric field at the capillary tip, and this leads to a reduction in charging of the surface of the liquid tip [24]. One may speculate that this in turn leads to reduced formation of highly charged droplets of very small radius, which are the most efficient sources of gas-phase ions [25].

\section{ESI Mass Spectra of DNA Nuçleotides in $100 \%$ $\mathrm{H}_{2} \mathrm{O}$ Analyte Signal Stability and Dynamic Range}

The results in Figures $2 b$ and $4 b$ showed the successful NTM ESI /MS analysis of NadCMP in aqueous solution when $\mathrm{SF}_{6}$ is used to suppress discharge. Under the same experimental conditions, very similar spectra were also obtained for neat aqueous solutions of sodium 5'-monophosphate of 2 '-deoxythymidine (TMP), 2'-deoxyadenosine monophosphate (dAMP), and $2^{\prime}$-deoxyguanosine monophosphate (dGMP). In all cases, the $[\mathrm{M}-\mathrm{H}]^{-}$peak was by far the major analyte ion. The dCMP, TMP, and dAMP had very similar $[\mathrm{M}-\mathrm{H}]^{-}$ion intensities, $10^{5} \mathrm{HZ}$ for $10^{-4} \mathrm{M}$ solutions, whereas dGMP led to an $\left[\mathrm{M}-\mathrm{H}^{-}\right.$ion of approximately $0.5 \times 10^{5} \mathrm{HZ}$.

The signal stability of the $[\mathrm{M}-\mathrm{H}]^{-}$ions obtained with ESI of $10^{-4} \mathrm{M}$ aqueous solutions of NadCMP and NadAMP observed in single-ion monitored plots was approximately $\pm 8 \%$. The electric discharge-generated

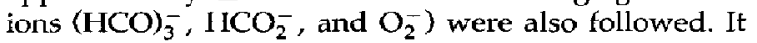
was found that the $\mathrm{O}_{2}^{-}$intensity fluctuated widely by close to a factor of 10 with rise times in the 1-s domain. It was shown in Figure 1 that the $\mathrm{O}_{2}^{-}$ion intensity was most strongly affected by the presence of $\mathrm{SF}_{6}$. The large fluctuations therefore should reflect turbulence and uneven mixing of the $\mathrm{SF}_{6}$ gas into the atmospheric gas near the capillary tip. Increase of the $\mathrm{SF}_{6}$ flow from 200 to $350 \mathrm{~mL} / \mathrm{min}$ decreased the $\mathrm{O}_{2}$ signal by a factor of approximately 2 to approximatcly $10^{3} \mathrm{HZ}$ and also its fluctuation. An increase in the $[\mathrm{M}-\mathrm{H}]^{-}$ signal stability to where the signal deviation was only $\pm 2 \%$ was also observed for these conditions. Still better analyte ion signal stabilities were obtained at lower solution flow rates such as $5 \mu \mathrm{L} / \mathrm{min}$.

The ESI/MS dynamic range in neat water is illustrated in Figure 5, which shows the change in TC and analyte ion $[\mathrm{M}-\mathrm{H}]^{-}$intensity with change in concentration of the analyte NadCMP. A linear region in the $\log -\log$ plot with slope approximately equal to unity is observed for the concentration range $10^{-7}-10^{-5} \mathrm{M}$. This region in which the ESI analyte ion intensity is proportional to the analyte ion concentration in the solution has been observed in PIM and discussed previously $[17,23]$. The gradual flattening out of the ion intensity above $10^{-5} \mathrm{M}$ solution concentrations (Figure 5b) also follows the typical pattern observed for PIM in previous work $[17,23]$. The ion intensities shown in Figure $5 b$ demonstrate that higher analyte ion intensities can be obtained at the lower solution flow rates of $4.5 \mu \mathrm{L} / \mathrm{min}$.
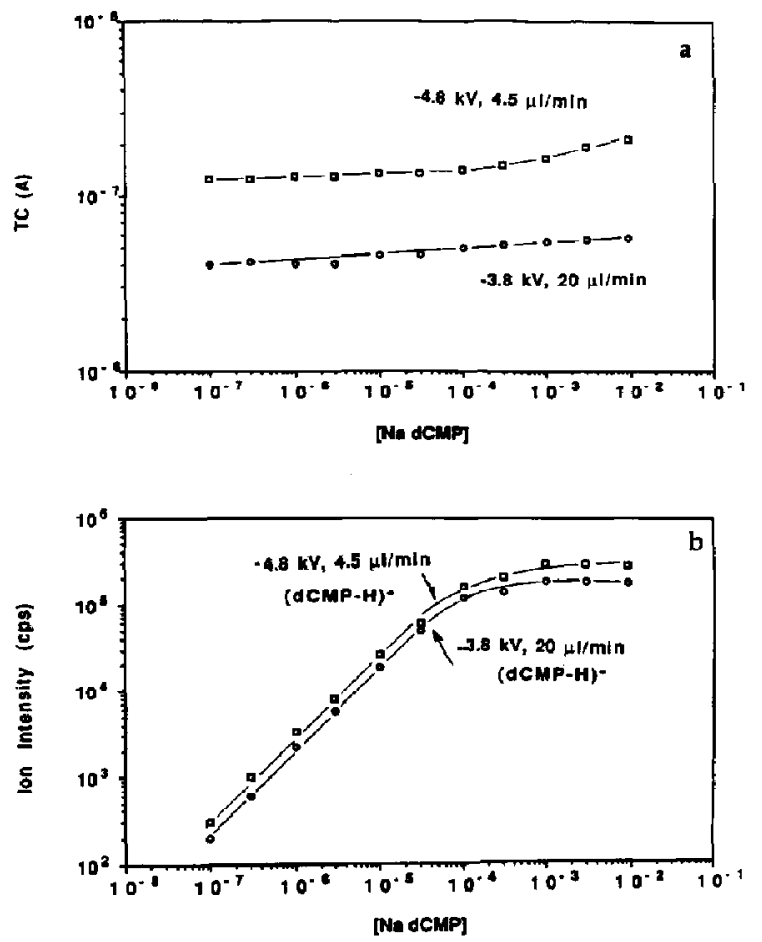

Figure 5. ESI/MS dynamic range for a typical nucleotide (dCMP). Plots of capillary TC and analyte ion [dCMP $-\mathbf{H}]^{-}$ intensity versus analyte concentration in moles per liter.

The detection limits for NadCMP can be estimated from data in Figure 5b. At $3 \times 10^{-7} \mathrm{M}$ analyte concentration, the detected ion intensity is approximately three times the signal deviation. For the approximately $8 \mathrm{~s}$ required to collect a mass spectrum, the required amount of analyte in solution at $4.5 \mu \mathrm{L}$ flow rates is approximately $0.2 \mathrm{pmol}$. This illustrates that very low detection limits are possible with aqueous solutions of analytes despite the problems created by the high surface tension of water and the enhanced propensity for electric discharge in the NIM.

\section{Conclusions}

Water relative to methanol and other solvents used in ESI has a much higher surface tension that requires higher capillary voltages for operation of ESI. This is predicted by theory [8] and observed by experiment in the present and previous work [15] from this laboratory.

The high ESI operating voltages required for water lead to the presence of simultaneous electric discharges that reduce the sensitivity for mass spectrometric detection of ESI analytes. The electric discharge can be suppressed and the analyte sensitivity improved by the application of $\mathrm{SF}_{6}$ gas. 
Comparisons between methanol and water as solvents in the NIM and PIM reveal the following features. The ESI onset voltages are the same for NIM and PIM, as predicted by theory [8]. Discharge onset occurs sooner and suppresses analyte ion detection sensitivity more severely for NIM than PIM. Owing to the low operating ESI voltage required for methanol, application of $\mathrm{SF}_{6}$ is of no advantage for PIM. Owing to the high operating ESI voltage required for water, electric discharge occurs for both NIM and PIM, and the application of $\mathrm{SF}_{6}$ is essential in both modes, however, for PIM it is still possible to obtain analyte ion signals without $\mathrm{SF}_{6}$, whereas for $\mathrm{NIM}$, analyte detection is very difficult without $\mathrm{SF}_{6}$.

The greater tendency toward electric discharge for NIM relative to PIM is attributed to electron emission for the metal capillary tip for NIM. Although the discharge problems are greatest with water in the NIM mode, the application of $\mathrm{SF}_{6}$ leads to stable ESI analyte ion signals and detection limits for nucleotide anions in the subpicomole range.

\section{Acknowledgment}

Financial support by the Premier's Council, Ontario Technology Fund is gratefully acknowledged.

\section{References}

1. Smith, R. D.; Loo, J. A.; Edmonds, C. G.; Barinaga, C. J.; Udseth, H. R. Amal. Chem. 1990, 62, 882-899.

2. McLuckey, S. A.; Van Berkel, G. T.; Glish, G. L. Proceedings of the 39th ASMS Conference on Mass Spectrometry and Alied Topics; Nashville, TN, May 1991; pp 981-982.

3. Covey, T. R.; Bonner, R. F.; Shushan, B. I.; Henion, J. D. Rapid Commun. Mass Spectrom. 1988, 2, 249-256.

4. Whitehouse, C. M.; Dreyer, R. N.; Yamashita, M.; Fenn, J. B. Anal. Chem. 1985, 57, 675-679.

5. Yamashita, M.; Fenn, J. B. Iyo Masu Kenkyukai Koenshu 1984, 9, 203-206.
6. McCloskey, J. A., Ed. Methods Enzymol. 1990, 193, 796-824.

7. Lang, H. R. M.; Rizzi, A. J. Chromatogr. 1986, 356, 115-122.

8. Smith, D. P. H. IEEE Trans. Ind. Appl. 1986, IA-22, 527-535.

9. (a) Smith, R. D.; Barinaga, C. J.; Udseth, H. R. Anal Chem. 1988, 60, 1948-1952; (b) Edmonds, C. G.; Loo, J. A.; Barmaga, C. J; Udseth, H. R.; Smith, R. D. J. Chromatogr. 1989, 171, 21.

10. Huang, E. C.; Wachs, T.; Conboy, J. J.; Henion, J. D. Anal. Chem. 1990, 62, 713A-725A.

11. Smith, R. D.; Olivares, J. A.; Nguyen, N. T.; Udseth, H. R. Anal. Chem., 1988, 60, 436-441.

12. Bruins, A. P.; Covey, T. R.; Henion, J. D. Anal Chem. 1987, $59,2642-2646$.

13. Chowdhury, S. K.; Chait, B. T. Anal. Chem. 1991, 63. 1660-1664.

14. Yamashita, M.; Fenn, J. B. I. Phys. Chem. 1984, 88, 4671-4675.

15. Ikonomou, M. G.; Blades, A. T.; Kebarle, P. I. Am. Soc. Mass Spectrom. 1991, 2, 497-505.

16. Loo, J. A.; Ogorzalek-Loo, R. R.; Light, K. J.; Edmonds, C. G.; Smith, R. D. Anal. Chem. 1992, 64, 81.

17. (a) Ikonomou, M. G.; Blades, A. T.; Kebarle, P. Anal. Chem. 1990, 62, 957-967; (b) Ikonomou, M. G.; Blades, A. T.; Kebarle, P. Anal. Chem. 1991, 63, 1989-1998; (c) Blades, A. T.; Ikonomou, M. G.; Kebarle. P. Anal. Chem. 1991, 63, 2109-2114.

18. (a) Fehsenfeld, F. C.; Ferguson, E. E. J. Chem. Phys. 1974, 61, 3181; (b) Payzant, J. D; Kebarle, P. J. Chem. Phys 1972, 56, $3482-3487$.

19. Smirnov, B. M. Negative lons; McGraw-Hill: New York, 1982; pp 21-47.

20. Meek, J. M.; Craggs, J. D., Eds. Electrical Breakdown of Gases; Wiley, New York, 1978; pp 319-384. Howatson, A. M. An Introduction to Gas Discharges, 2nd ed.; Pergamon Press, Elmont, NY, 1976.

21. (a) Grimsrud, E. P.; Chowdhury, S.; Kebarle, P. I. Chem. Phys. 1985, 83, 1059; (b) Knighton, W. B.; Zook, D. R.; Grimsrud, E. P. J. Arr. Suc. Mass Specirom. 1990, 1, 372.

22. Tang, L.; Kebarle, P. Anal. Chem., submitted.

23. Tang, L.; Kebarle, P. Anal. Chem. 1991, 63, 2709-2715.

24. Ferun, J. D.; Mann, M.; Meng, C. K.; Wong, S. F.; Whitehouse, C. M. Science 1989, 246, 64-71.

25. Fernandez de la Mora, J.; Rosell-Llompart, J. Proceedings of the 39th ASMS Conference on Mass Spectrometry and Allied Topics; Nashville, TN, May 1991; pp 441-442. 